\title{
Magnitude of overweight and associated factors among type 2 diabetes mellitus patients at Mekelle public hospitals, Tigray, Ethiopia: a cross-sectional study
}

\author{
Kbrom Gemechu Kiros ${ }^{1 *}$, Gebre Yitayih Abyu ${ }^{2}$, Desta Siyoum Belay ${ }^{3}$, Mekonnen Haftom Goyteom ${ }^{1}$ \\ and Tensay Kahsay Welegebriel ${ }^{3}$
}

\begin{abstract}
Objective: To assess magnitude of overweight and associated factors among type 2 diabetes mellitus patients at Mekelle public hospitals, Tigray, Ethiopia.

Results: A total of 365 participants were enrolled in this study. One hundred ninety-eight (54.2\%) of the participants were males and 288 (78.9\%) of the study participants were from an urban residence. In this study 161 (44.1\%) and 12 (3.3\%) of the study subjects were alcohol consumers and smokers respectively. Besides, 166 (45\%) of the study participants had poor dietary intake and around $302(82.7 \%)$ had low level of vigorous physical activity. The proportion of individuals who were overweight using body mass index as a measure was 149 (40.8\%) and the proportion of individuals who had central obesity using waist circumference as a measure was 194 (53.2\%). The magnitude of overweight among study participants from urban residence and alcohol consumers was 138 (92.6\%) and 93 (62.4\%) respectively. Residence area, alcohol consumption, physical activities, central obesity and dietary intake were the determinant factors for overweight among type 2 diabetes mellitus patients.
\end{abstract}

Keywords: Overweight, Determinant factors, Type 2 diabetes mellitus

\section{Introduction}

Globally, more than 1.9 billion adults aged 18 years and above were overweight in 2016. Of these, over 650 million adults were obese [1]. In Sub-Saharan African (SSA) countries the magnitude of overweight is increasing at an alarming rate [2]. This is due to rapid urbanization, dramatic lifestyle changes and high prevalence of child hood stunting [3]. Overweight has been an issue in developed countries for the past years. However, currently, it has gained attention in developing countries as an issue that needs to be addressed [4]. Overweight in people with diabetes could induce increased thrombogenic factors, cardiovascular disease and raised blood pressure. It also

\footnotetext{
*Correspondence: kbromgemechu@gmail.com

${ }^{1}$ Department of Nursing, Adigrat University, Adigrat, Ethiopia

Full list of author information is available at the end of the article
}

interferes with the treatment of hyperglycemia and diabetes-related complications $[5,6]$.

In Ethiopia, magnitude of overweight is increasing among type $2 \mathrm{DM}$ patients. However, data on overweight of type 2 DM patients is limited because priority has always been given to under nutrition and communicable diseases $[7,8]$. Besides, previous studies predominantly relied on body mass index (BMI) as measure of overweight. However, our study used both BMI and waist circumference to measure overweight. Therefore, the aim of this study was to assess magnitude of overweight and associated factors among type $2 \mathrm{DM}$ patients.

\section{Main text}

Study area, design, period and participants

The study was conducted from February to April, 2018 by using cross-sectional study design in Mekelle public 
hospitals, Tigray, Ethiopia. All type 2 DM patients who were available at the time of data collection period were included and patients who had severe illness or physical disability, pregnant mothers and patients with edema were excluded from this study.

\section{Sample size determination and sampling technique}

A single population proportion formula was used. The estimated proportion of overweight among type $2 \mathrm{DM}$ patients was $31.5 \%$ [8]. Accordingly, the required sample size (n) was estimated with a confidence level of 95\%, 5\% margin of error and by adding $10 \%$ non-response rate the final sample size was 365 .

Systematic random sampling method was used to select the study participants from a total of 2442 type 2 DM patients who were on treatment follow up in Mekelle public hospitals. To select the required sample size the total sample size was proportionally allocated to the three public hospitals. Accordingly, the list of the patients was taken from the follow up unit of the three public hospitals and sampling frame was developed. Then the first study subject was randomly selected from the sampling frame by using lottery method and based on the sampling interval $(k=6)$ every six interval was selected from the sampling frame. Finally, 365 of patients with type 2 DM were included in our study.

\section{Data collection tools and procedures}

The tools for data collection include a portable Stadiometer, stretch-resistant tape meter and structured questionnaire. The questionnaire was composed of questions on socio-demographic data, behavioral and health-related factors, dietary factors and anthropometric measurement (weight, height and waist circumference).

The data was collected using a structured questionnaire through face to face interview and physical measurements of weight, height, waist circumferences using standardized techniques and calibrated equipment. Weight and height were measured with participants standing without shoes and wearing light clothing. Participants were standing upright with the head, shoulder, buttock, lower limb and heal of the foot touches the height board for height measurement. Waist circumference was measured midway between the lower rib margin and the iliac crest in the horizontal plane using a tape meter by following the standard procedure.

\section{Data quality control}

The questionnaire was initially prepared in English and translated to Tigrigna language then back to the English language. One day training was given on the objective of the study, instrument and data collection procedures by the principal investigator for the data collectors and supervisors. The weight measurement scale was checked if it is at zero before each measurement. Five percent of the questionnaire was tested before the actual data collection period outside of the study area. Data collectors were instructed to check the completeness of the instrument just after its completion. The principal investigator checked out the questionnaire for completeness each night. Moreover, the collected data were coded, cleaned and explored before analysis to check missing items and completeness of the collected data.

\section{Operational definitions}

Overweight BMI greater than or equals to $25 \mathrm{~kg} / \mathrm{m}^{2}$.

Central obesity waist circumference greater than $88 \mathrm{~cm}$ for females and greater than $102 \mathrm{~cm}$ for males was considered as having abdominal obesity.

Low level of physical exercise individual activity less than 150 min per week was considered as low level of physical activities.

Adequate level of physical exercise individual activity above 150 min per week was considered as adequate level of physical activities.

Dietary intake level of dietary intake was determined based on dietary factors questionnaire. Six items were asked and based on the mean value of those questions individuals who score below the mean value were classified as poor and those who score above the mean value were classified as good dietary practices.

\section{Data processing and analysis}

The collected data were entered and cleaned using Epidata manager. Two items of dietary questions were reversely coded to explain total score to be interpreted as higher scores meaning better outcomes. Then it was exported to SPSS version 21 for statistical analysis. Descriptive statistics were computed using the frequency table and numerical summary measures. Binary logistic regression was done to determine the magnitude, direction and strength of association between a set of independent variables and the outcome variable at $\mathrm{p}<0.25$ significance level. Then those variables that were significant at $\mathrm{p}<0.25$ with the outcome variable were selected for multivariable analysis. Odds ratio with $95 \%$ confidence level was computed and significant association was declared at $\mathrm{p}$-value $<0.05$. Finally, the result was presented using text and tables.

\section{Results}

\section{Socio-demographic characteristics}

A total of 365 participants were enrolled in this study. One hundred ninety-eight (54.2\%) of the participants were males. Two hundred seventy (74\%) of the study subjects were Orthodox followers. Besides, 288 (78.9\%) 
of the study participants were from an urban setting and 291 (79.7\%) were married (Table 1).

Behavioral factors and dietary intake of type $2 \mathrm{DM}$ patients Out of 365 respondents, 161 (44.1\%) and 12 (3.3\%) of the study subjects were alcohol consumers and smokers respectively. About 247 (67.7\%) of the study subjects had a habit of walking on their daily living and 302 (82.7\%) had low level of vigorous physical activity. In our study 199 (55\%) of the study participants had good dietary intake and 166 (45\%) had poor dietary intake. Of these,

Table 1 Socio-demographic characteristics of type 2 diabetes mellitus patients at Mekelle public hospitals, Tigray, Ethiopia, 2018

\begin{tabular}{|c|c|c|}
\hline Variables & Number & Percent \\
\hline \multicolumn{3}{|l|}{ Sex } \\
\hline Male & 198 & 54.2 \\
\hline Female & 167 & 45.8 \\
\hline \multicolumn{3}{|l|}{ Age } \\
\hline $25-34$ & 30 & 8.2 \\
\hline $35-44$ & 71 & 19.5 \\
\hline $45-54$ & 133 & 36.4 \\
\hline Above 55 years & 131 & 35.9 \\
\hline \multicolumn{3}{|l|}{ Marital status } \\
\hline Single & 12 & 3.3 \\
\hline Married & 291 & 79.7 \\
\hline Divorced & 25 & 6.8 \\
\hline Widowed & 37 & 10.2 \\
\hline \multicolumn{3}{|l|}{ Religion } \\
\hline Orthodox & 270 & 74 \\
\hline Muslim & 78 & 21.4 \\
\hline Others & 17 & 4.6 \\
\hline \multicolumn{3}{|l|}{ Ethnicity } \\
\hline Tigray & 354 & 97 \\
\hline Amhara & 11 & 3 \\
\hline \multicolumn{3}{|l|}{ Educational status } \\
\hline Can't read and write & 74 & 20.3 \\
\hline Primary & 94 & 25.8 \\
\hline Secondary & 72 & 19.7 \\
\hline Diploma and above & 125 & 34.2 \\
\hline \multicolumn{3}{|l|}{ Occupational status } \\
\hline Housewife & 87 & 23.8 \\
\hline Government employee & 127 & 34.8 \\
\hline Merchant & 83 & 22.7 \\
\hline Farmer & 40 & 11 \\
\hline Retired & 18 & 4.9 \\
\hline Other & 10 & 2.7 \\
\hline \multicolumn{3}{|l|}{ Residential area } \\
\hline Rural & 77 & 21.1 \\
\hline Urban & 288 & 78.9 \\
\hline
\end{tabular}

333 (91.2\%) had got nutritional education from different sources and $32(8.8 \%)$ individuals didn't have nutritional education from any sources.

\section{Magnitude of overweight}

The magnitude of overweight among type $2 \mathrm{DM}$ patients using BMI as a measure was 149 (40.8\%) [95\% CI (35.7, 46)] and by using waist circumference as a measure 194 (53.2\%) of the study subjects had central obesity (Table 2).

\section{Factors associated with overweight}

Being from urban residence had 3.4 times the odds of being overweight compared to their counterparts $[\mathrm{AOR}=3.4,95 \% \mathrm{CI}(1.26-9.4)]$. The odds of overweight

Table 2 Magnitude of overweight by socio-demographic characteristics among type 2 diabetes mellitus patients at Mekelle public hospitals, Tigray, Ethiopia, 2018

\begin{tabular}{|c|c|c|c|}
\hline \multirow[t]{3}{*}{ Variable } & \multirow[t]{3}{*}{ Category } & \multicolumn{2}{|l|}{ Overweight } \\
\hline & & No & Yes \\
\hline & & Number (\%) & Number (\%) \\
\hline \multirow[t]{2}{*}{ Sex } & Male & $122(56.5)$ & $76(51)$ \\
\hline & Female & $94(43.5)$ & $73(49)$ \\
\hline \multirow[t]{4}{*}{ Age category } & $25-34$ & $21(9.7)$ & $9(6)$ \\
\hline & $35-44$ & $61(28.2)$ & $10(6.7)$ \\
\hline & $45-54$ & $83(38.4)$ & $50(33.6)$ \\
\hline & Above 55 & $51(23.6)$ & $80(53.7)$ \\
\hline \multirow[t]{4}{*}{ Marital status } & Single & $8(3.7)$ & $4(2.7)$ \\
\hline & Married & $171(79.2)$ & $120(80.5)$ \\
\hline & Divorced & $17(7.9)$ & $8(5.4)$ \\
\hline & Widowed & $20(9.3)$ & $17(11.4)$ \\
\hline \multirow[t]{3}{*}{ Religion } & Orthodox & $186(86.1)$ & $84(56.4)$ \\
\hline & Muslim & $25(11.6)$ & $53(35.6)$ \\
\hline & Others & $5(2.3)$ & $12(8)$ \\
\hline \multirow[t]{2}{*}{ Ethnicity } & Tigray & $208(96.3)$ & $146(98 \%)$ \\
\hline & Amhara & $8(3.7)$ & $3(2)$ \\
\hline \multirow[t]{5}{*}{ Educational status } & Can't read and write & $52(24.1)$ & $22(14.8)$ \\
\hline & $\begin{array}{l}\text { Non formal educa- } \\
\text { tion }\end{array}$ & $1(0.5)$ & $0(0.0)$ \\
\hline & Primary school & $56(26)$ & $38(25.5)$ \\
\hline & Secondary school & $42(19.4)$ & $30(20.1)$ \\
\hline & Diploma and above & $66(30.6)$ & $59(39.6)$ \\
\hline \multirow[t]{6}{*}{ Occupational status } & Housewife & $48(22.2)$ & $39(26.2)$ \\
\hline & $\begin{array}{l}\text { Government } \\
\text { employee }\end{array}$ & $86(39.8)$ & $41(27.5)$ \\
\hline & Merchant & $34(15.7)$ & $49(32.9)$ \\
\hline & Farmer & $35(16.2)$ & $5(3.4)$ \\
\hline & retried & $5(2.3)$ & $13(8.7)$ \\
\hline & Other & $8(3.7)$ & $2(1.3)$ \\
\hline \multirow[t]{2}{*}{ Residential area } & Rural & $66(30.6)$ & $11(7.4)$ \\
\hline & Urban & $150(69.4)$ & 138 (92.6) \\
\hline
\end{tabular}


among participants who stayed with type $2 \mathrm{DM}$ for 3-6 years was 2.8 times higher compared to those who stayed less than 3 years $[\mathrm{AOR}=2.8,95 \% \mathrm{CI}(1-7.85)]$. Study participants who were alcohol consumers were 2.9 times more likely to develop overweight compared to non-consumers $[\mathrm{AOR}=2.9,95 \% \mathrm{CI}(1.5-5.5)]$. Overweight was 4 times higher among peoples with type 2 diabetes mellitus who had low level of vigorous physical activity as compared with study subjects who had adequate level of vigorous physical activity $[\mathrm{AOR}=4,95 \%$ CI (1.19-13.8)]. Besides, study subjects who did not walk regularly were 2.3 times more likely to have overweight as compared to their counterpart $[\mathrm{AOR}=2.3,95 \% \mathrm{CI}(1-5.17)]$. Concerning dietary intake, the odds of being overweight increased by nearly 8 times in type $2 \mathrm{DM}$ patients with poor dietary intake $[\mathrm{AOR}=7.9,95 \% \mathrm{CI}(4.02-15.5)]$ (Table 3$)$.

\section{Discussion}

In this study, the overall magnitude of overweight was $40.8 \%$ [95\% CI $(35.7,46)]$. This is almost similar to the study done in Addis Ababa, and Hosanna [7, 8]. However, it is lower than the study done in India, Nepal and Bahrain $[9-11]$. This difference might be due to variation in

Table 3 Factors associated with overweight among type 2 diabetes mellitus patients at Mekelle public hospitals, Tigray, Ethiopia, 2018

\begin{tabular}{|c|c|c|c|c|c|c|}
\hline \multirow[t]{2}{*}{ Variable } & \multirow[t]{2}{*}{ Category } & \multicolumn{2}{|c|}{ Overweight } & \multirow[t]{2}{*}{ COR $(95 \% \mathrm{CI})$} & \multirow[t]{2}{*}{ AOR $(95 \% \mathrm{Cl})$} & \multirow[t]{2}{*}{$p$ value } \\
\hline & & No & Yes & & & \\
\hline \multirow[t]{4}{*}{ Age } & $25-34$ & $21(9.7)$ & $9(6)$ & 1 & 1 & \\
\hline & $35-44$ & $61(28.2)$ & $10(6.7)$ & $0.4(0.14,1.07)$ & $0.7(0.18,2.97)$ & 0.658 \\
\hline & $45-55$ & $83(38.4)$ & $50(33.6)$ & $1.4(0.6,3.31)$ & $1.4(0.41,5.05)$ & 0.573 \\
\hline & $>55$ years & $51(23.6)$ & $80(53.7)$ & $3.66(1.55-8.61)$ & $3.5(0.9,12.3)$ & 0.051 \\
\hline \multirow[t]{2}{*}{ Residence area } & Rural & $66(30.6)$ & $11(7.4)$ & 1 & 1 & \\
\hline & Urban $^{* *}$ & 150 (69.4) & 138 (92.6) & $5.52(2.8,10.9)$ & $3.4(1.26,9.4)$ & 0.016 \\
\hline \multirow[t]{2}{*}{ Alcohol drink } & Yes $^{* *}$ & $68(31.5)$ & $93(62.4)$ & $3.61(2.33-5.6)$ & $2.9(1.5,5.5)$ & 0.001 \\
\hline & No & $148(68.5)$ & $56(37.6)$ & 1 & 1 & \\
\hline \multirow[t]{5}{*}{ Alcohol drink frequency } & 7 days/week & $6(2.8 \%)$ & $11(7.4)$ & $4.7(1.67,13.38)$ & $1.2(0.02,15)$ & 0.932 \\
\hline & 5-6 days/week & $10(4.6 \%)$ & $16(10.7)$ & $4.1(1.76,9.62)$ & $0.2(0.006,8.03)$ & 0.414 \\
\hline & 1-4 days/week & $17(7.9)$ & $23(15.4)$ & $3.4(1.73,7.00)$ & $0.3(0.01,10.12)$ & 0.518 \\
\hline & 1 day/week & $35(16.2)$ & $42(28.2)$ & $3(1.79,5.32)$ & $0.2(0.007,5.9)$ & 0.359 \\
\hline & Not drink & $148(69.5)$ & $57(38.3)$ & 1 & 1 & \\
\hline \multirow[t]{2}{*}{ Vigorous activity } & Yes & $85(39.4)$ & $24(16.1)$ & 1 & 1 & \\
\hline & No & $131(60.6)$ & $125(83.9)$ & $3.37(2,5.65)$ & $1.2(0.48,3.18)$ & 0.656 \\
\hline \multirow[t]{2}{*}{ Moderate activity } & Yes & $94(43.5)$ & $40(26.8)$ & 1 & 1 & \\
\hline & No & $122(56.5)$ & $109(73.2)$ & $2.1(1.33,3.29)$ & $0.7(0.27,1.66)$ & 0.390 \\
\hline \multirow[t]{2}{*}{ Walk } & Yes & $182(84.3)$ & 65 (43.6) & 1 & 1 & \\
\hline & $\mathrm{No}^{* *}$ & $34(15.7)$ & $84(56.4)$ & $6.9(4.24,11.27)$ & $2.3(1.01,5.17)$ & 0.045 \\
\hline \multirow[t]{2}{*}{ Central obesity } & Yes $^{* *}$ & $73(33.80$ & $121(81.2)$ & $8.46(5.14,13.9)$ & $3.4(1.64,6.91)$ & 0.001 \\
\hline & No & $143(66.2)$ & $28(18.8)$ & 1 & 1 & \\
\hline \multirow[t]{3}{*}{ Duration of DM } & $0-3$ years & $69(31.9)$ & $22(14.8)$ & 1 & 1 & \\
\hline & 3-6 years ${ }^{* *}$ & $46(21.3)$ & $32(21.5)$ & $2.1(1.12,4.21)$ & $2.8(1,7.85)$ & 0.039 \\
\hline & $>6$ years & $101(46.8)$ & $95(63.8)$ & $3(1.69,5.14)$ & $2.5(1.08,5.74)$ & 0.031 \\
\hline \multirow[t]{2}{*}{ Dietary intake } & Good & $160(74.1)$ & $39(26.2)$ & 1 & 1 & \\
\hline & Poor** & $56(25.9)$ & $110(73.8)$ & $8(5.00,12.96)$ & $8(4.02,15.5)$ & 0.000 \\
\hline \multirow[t]{2}{*}{ Vigorous activity } & Adequate & $58(26.9)$ & $5(3.4)$ & 1 & 1 & \\
\hline & $\operatorname{Low}^{* *}$ & $158(73.1)$ & $144(96.6)$ & $10.5(4.12,27)$ & $4(1.19,13.8)$ & 0.025 \\
\hline \multirow[t]{2}{*}{ Moderate activity } & Adequate & $70(32.4)$ & $16(10.7)$ & 1 & 1 & \\
\hline & Low & 146 (67.6) & $133(89.3)$ & $3.98(2.2,7.20)$ & $2.1(0.89,4.97)$ & 0.089 \\
\hline \multirow[t]{2}{*}{ Walk level } & Adequate ${ }^{* *}$ & 131 (60.6) & $24(16.1)$ & 1 & 1 & \\
\hline & Low & $85(39.4)$ & $125(83.9)$ & $8(4.76,13.43)$ & $3.3(1.45,7.61)$ & 0.005 \\
\hline
\end{tabular}

COR Crude Odd Ratio, AOR Adjusted Odd Ratio, Cl confidence interval

** $\mathrm{p}$ value $<0.05$ significant 
socio-demographic factors, lifestyle, and economic status. In this study, using waist circumference as an indicator yielded the highest magnitude of obesity compared to using BMI. By using waist circumference as a measure $53.2 \%$ of the study subjects had central obesity that is higher as compare to the general obesity (40.8\%). In general, this finding indicates that using BMI alone underestimate the magnitude of overweight or obesity.

Dietary intake was also the other variable that had significant association with overweight among type $2 \mathrm{DM}$ patients. This is in line with the study done in Addis Ababa, Ethiopia [7]. It is also supported by study done in South Africa [12]. The reason might be due to rapid nutrition transition in developing countries and lack of nutritional education. There was also a statistically significant association between overweight and physical activities. This finding is in line with a study done in South Africa, Yemen, and Ghana where physical activity was significantly associated with overweight [12-14]. This might be due to high in sedentary behavior and poor motivation to physical exercise.

Residence area was the other variable that had a significant association with overweight in this study. Being from urban residence had 3.4 times odds of being overweight. The possible reason might be due exposure of urban population to unhealthy lifestyle, high proportion of urban study subjects in the current study and participants from rural area were more physically active. It is also showed that duration of diabetes after diagnosis was significantly associated with overweight. However, it contradicts with the finding reported from Yemen and Kenya which reports, the occurrence of overweight decreases with the duration of DM after diagnosis $[13,15]$. So, this contradicting issue needs further investigation. Previous studies reported that being female associated with overweight however in this study sex had no significant association with overweight $[9,10]$. This might be due to variation in socio-demographic factors.

\section{Conclusion and recommendations}

The magnitude of overweight was high among type $2 \mathrm{DM}$ patients. The determinant factors were residence area, alcohol consumption, low level physical activities, duration of DM, central obesity and dietary intake. Using waist circumference in conjunction with BMI would be useful for better diagnosis and early detection of overweight among type $2 \mathrm{DM}$ patients. Researcher should have to investigate perceived barriers to regular physical activity among type $2 \mathrm{DM}$ patients.

\section{Limitations of the study}

- There might be recall bias among respondents answering questions related to dietary intake of the week, time spent for doing physical activity and sitting/reclining on a typical day.

- Nutritional knowledge and genetic susceptibility of the respondent to overweight was not considered.

\section{Abbreviations}

AOR: Adjusted Odds Ratio; BMI: body mass index; Cl: confidence interval; COR: Crude Odds Ratio; DM: diabetes mellitus; SPSS: Statistical Package for Social Sciences; SSA: Sub-Saharan Africa; WC: waist circumference.

\section{Acknowledgements}

First and for most, we thank Mekelle University, school of nursing for its financial support. Our recognition also goes to data collectors, supervisors, workers at diabetic clinic and authorities of Mekelle public hospitals who were facilitating the data collection. Finally, we would like to thank the study participants who were willing to take part in this study.

\section{Author's contributions}

KGK conceived the idea of the study, prepared the study proposal, supervised the data collection in the field, performed the data analysis, and drafted the manuscript. GYA, DSB, MHG, and TKW assisted with the preparation of the proposal and the interpretation of data, participated in data analysis. They also participated in the interpretation of data and critically reviewed the manuscript. All authors participated in the revision of the manuscript. All authors read and approved the final manuscript.

\section{Funding}

Mekelle University. The funder has no role in the design, analysis, preparation of the manuscript and decision to publish.

\section{Availability of data and materials}

The datasets used and analyzed during this study are available from the corresponding author on reasonable request.

\section{Ethics approval and consent to participate}

Ethical clearance and approval was obtained from Mekelle University ethical review committee. Official letter was written from Tigray regional health bureau to each hospital and letter of permission was obtained from the medical director office to communicate with relevant bodies at the hospitals. All participants recruited to this study were informed about the purpose of the study, the right to participate or to terminate at any time if they want and they were ensured about the confidentiality of information. Finally, written consent was obtained from all the study participants.

Consent to publish

Not applicable for this section.

Computing interests

All authors declare that they have no competing interests.

\section{Author details}

${ }^{1}$ Department of Nursing, Adigrat University, Adigrat, Ethiopia. ${ }^{2}$ Department of Nursing, Bahirdar University, Bahir Dar, Ethiopia. ${ }^{3}$ Department of Nursing, Mekelle University, Mekelle, Ethiopia.

Received: 3 October 2019 Accepted: 11 November 2019 Published online: 21 November 2019 


\section{References}

1. World Health Organization. Global overweight and obesity fact sheet report. https://www.who.int/news-room/fact-sheets/detail/obesity-andoverweight. Accessed 23 Apr 2017.

2. Abrha S, Shiferaw S, Ahmed KY. Overweight and obesity and its sociodemographic correlates among urban Ethiopian women: evidence from the 2011 EDHS. BMC Public Health. 2016;16(1):636.

3. Tuei VC, Maiyoh GK, Ha CE. Type 2 diabetes mellitus and obesity in subSaharan Africa. Diabetes Metab Res Rev. 2010;26(6):433-44.

4. $\mathrm{Ng} \mathrm{CD}$. Global analysis of overweight prevalence by level of human development. J Glob Health. 2015;5(2):020413.

5. Obulutsa JN. Rural urban prevalence and associated factors of overweight and obesity in adult patients seeking health care: a case of Pcea Kikuyu Hospital, Kenya. Nairobi: University of Nairobi; 2015.

6. Kivimäki $M$, et al. Overweight, obesity, and risk of cardiometabolic multimorbidity: pooled analysis of individual-level data for 120813 adults from 16 cohort studies from the USA and Europe. Lancet Public Health. 2017;2(6):e277-85.

7. Worku A, Abebe SM, Wassie MM. Dietary practice and associated factors among type 2 diabetic patients: a cross sectional hospital based study, Addis Ababa, Ethiopia. SpringerPlus. 2015;4(1):15.

8. Gudina E, Bizatu M, Abera L. Prevalence of overweight/obesity and associated factors among type 2 diabetic patients at Nigist Elleni Memorial Hospital, Hosanna Town, Southern, Ethiopia. Dire Dawa: Harmaya University; 2017.

9. Kamath A, Shivaprakash G, Adhikari P. Body mass index and waist circumference in type 2 diabetes mellitus patients attending a diabetes clinic. Int J Biol Med Res. 2011;2(3):636-8
10. Basukala A, Sharma M, Pandeya A. Prevalence of overweight and obesity among patients with type 2 diabetes mellitus in Kathmandu. Age (years). 2014;36(85.00):57.41.

11. Shamsi $N$, et al. Factors influencing dietary practice among type 2 diabetics. Bahrain Med Bull. 2013;35(3):130-5.

12. Okonta HI, Ikombele JB, Ogunbanjo GA. Knowledge, attitude and practice regarding lifestyle modification in type 2 diabetic patients. Afr J Prim Health Care Fam Med. 2014;6(1):1-6.

13. Al-Sharafi BA, Gunaid AA. Prevalence of obesity in patients with type 2 diabetes mellitus in Yemen. Int J Endocrinol Metab. 2014;12(2):e13633.

14. Obirikorang Y, et al. Knowledge and lifestyle-associated prevalence of obesity among newly diagnosed type II diabetes mellitus patients attending diabetic clinic at Komfo Anokye teaching hospital, Kumasi, Ghana: a hospital-based cross-sectional study. J Diabetes Res. 2016;2016:10

15. Mogre V, Abedandi R, Salifu ZS. Prevalence of obesity and systemic hypertension among diabetes mellitus patients attending an out-patient diabetes clinic in a Ghanaian Teaching Hospital. Diabetes Metab Syndr Clin Res Rev. 2014;8(2):67-71.

\section{Publisher's Note}

Springer Nature remains neutral with regard to jurisdictional claims in published maps and institutional affiliations.
Ready to submit your research? Choose BMC and benefit from:

- fast, convenient online submission

- thorough peer review by experienced researchers in your field

- rapid publication on acceptance

- support for research data, including large and complex data types

- gold Open Access which fosters wider collaboration and increased citations

- maximum visibility for your research: over $100 \mathrm{M}$ website views per year

At BMC, research is always in progress.

Learn more biomedcentral.com/submissions 